\title{
RELACIONAMENTOS INTERORGANIZACIONAIS EM EMPRESAS DE PEQUENO PORTE E SUA INSERÇÃO EM CADEIAS DE SUPRIMENTOS
}

\author{
INTERORGANIZATIONAL RELATIONSHIPS IN SMALL SIZED \\ BUSINESSES AND THEIR INSERTION IN SUPPLY CHAINS
}

\author{
Data de submissão: 19-12-2013 \\ Aceite: $21-12-2014$ \\ Leonardo Pinheiro Deboçã ${ }^{1}$ \\ Ricardo Silveira Martins²
}

\section{RESUMO}

Este artigo buscou contribuir para a compreensão de como se configuram os relacionamentos horizontais e verticais de pequenas e médias empresas (PMEs) e quais são seus desdobramentos para estas empresas em sua inserção em cadeias de suprimentos. Para tanto, foram utilizadas experiências de empresas moveleiras localizadas em polos industriais. Esta foi uma pesquisa qualitativa e quantitativa, desenvolvida por meio de um estudo comparativo dos polos moveleiros de Mirassol (São Paulo) e Ubá (Minas Gerais). Os dados foram coletados por meio de entrevistas semiestruturadas junto a entidades de apoio e empresas nos polos. A pesquisa revelou a dificuldade destas empresas de desenvolverem relacionamentos colaborativos, o que é uma barreira para a integração em cadeia de suprimentos. Além da baixa disposição a relacionamentos mais próximos, a pesquisa revelou ausência de estratégias definidas quanto a fornecedores e clientes, demonstrando inclinação para práticas transacionais. O comportamento mercadológico das PMEs e as características das práticas de governança criam dificuldades para a inserção destas empresas em cadeias de suprimentos como fornecedores, implicando, dessa forma, seu posicionamento como produtoras de bens finais e, portanto, como concorrentes de empresas de maior porte.

Palavras-chave: Gestão de relacionamentos. Pequenas e médias empresas. Cadeias de suprimentos.

\footnotetext{
${ }^{1}$ Possui graduação em Administração de Cooperativas pela Universidade Federal de Viçosa, UFV, mestrado em Administração pela Universidade Federal do Paraná, UFPR e doutorado em Administração pela Universidade Federal de Minas Gerais, UFMG. Rio Parnaíba. Minas Gerais. Brasil. E-mail: leonardopd@gmail.com

${ }^{2}$ Possui graduação em Ciências Econômicas pela Universidade Federal de Viçosa, UFV, mestrado em Economia Aplicada pela Universidade Federal de Viçosa, UFV e doutorado em Ciências (Economia Aplicada) pela Universidade de São Paulo, USP. Belo Horizonte. Mias Gerais. Brasil. E-mail: ricardomartins.ufmg@gmail.com
} 


\begin{abstract}
This research sought to contribute to the understanding of how to configure the horizontal and vertical Small and Medium Enterprises (SMEs) relationships and which are the consequences for these firms in their insertion in supply chains. To this end, furniture companies data located in industrial district were used. This was a qualitative and quantitative research, developed through a comparative study of furniture companies located at Mirassol (São Paulo) and Ubá (Minas Gerais) poles. Data were collected through semi-structured interviews with support entities and businesses. The survey revealed the difficulty of these firms in developing collaborative relationships, what mean a barrier to integration of the supply chain. Besides the low inclination to closer relationships, the research revealed absence of strategies defined as suppliers and customers, showing inclination to transactional practices. The SMEs market behavior and characteristics of governance practices create difficulties for the inclusion of these companies into supply chains as suppliers, thus leaving the positioning as final goods producers, as competitors of larger companies.
\end{abstract}

Keywords: Relationships management. Small and medium sized enterprises. Supply chain.

\title{
1 INTRODUÇÃO
}

Na busca pela compreensão do que faz uma firma ter melhor desempenho que suas concorrentes, o campo da ciência da Administração voltado à estratégia tem descoberto evidências do importante papel dos relacionamentos. Dessa forma, a relevância da análise dos relacionamentos desenvolvidos pela firma reside na constatação de que a competitividade emerge não só dos recursos internos presentes na organização possui, mas também daqueles acessados por ela por intermédio de sua rede de relacionamentos (DYER; SINGH, 1998).

Chen e Paulraj (2004) contextualizam as transformações nas teorias e práticas de mercado no âmbito das alterações no modelo de negócio, em que a maior parte do valor entregue pelas empresas tende a estar nos serviços agregados aos produtos, levando à noção de que as empresas individuais são elos de uma cadeia. Uma forma de abordar estas cadeias ou redes de relacionamentos interorganizacionais é o paradigma conhecido como cadeia de suprimentos, que tem sido apontado como poderosa estratégia de potencialização do valor tanto para o cliente quanto para os participantes de determinada cadeia. Trata-se, em suma, de uma estrutura de integração entre diferentes organizações com objetivos comuns.

De um lado, as pequenas e médias empresas (PMEs) podem ter posição desvantajosa nos relacionamentos no contexto do novo modelo de negócio, em razão do seu porte e das relações de poder nos relacionamentos e nas negociações. Conforme Torres Jr. e Ratão (2011), este é um assunto ainda pouco desenvolvido na literatura especializada.

De outro lado, quando posicionadas em aglomerações espaciais, as PMEs encontram oportunidades para superarem alguns dos desafios advindos do seu porte. Dentre estes, podem ser destacados a dificuldade de acesso e atualização à tecnologia; a condição de formar e de competir pela mão de obra especializada, o que pode gerar dificuldades para a aplicação das ferramentas disponíveis para o controle da produção (SLACK; CHAMBERS; JOHNSTON, 2007); e a adaptação ao mercado, que pode se dar mais lentamente, devido ao reduzido nível de organização contábil, o que dificulta o alinhamento entre as estratégias de produção e de negócios, bem como a implementação de ações e de ferramentas de gestão e produção (MDIC, 2007).

Dessa forma, é pertinente a avaliação dos relacionamentos entre PMEs e seus fornecedores e clientes, assim como entre tais empresas e entidades dos polos. A proposta deste artigo consiste, então, em investigar as relações entre relacionamentos interorganizacionais em PMEs 
e seus desdobramentos em contextos de cadeias de suprimento. Assim, a pergunta colocada é: como se configuram os relacionamentos horizontais e verticais e quais seus desdobramentos em termos da inserção das organizações em cadeias de suprimentos? Para tanto, foram utilizadas experiências de empresas moveleiras localizadas em polos industriais.

Os polos moveleiros constituem-se em um campo empírico potencialmente rico para a pesquisa, notadamente pela nítida coexistência entre as relações verticais (fornecedores e clientes) e as relações horizontais (entidades de apoio e demais empresas moveleiras) decorrentes da concentração geográfica dessas empresas. Esse setor industrial é formado, predominantemente, por micro e pequenas empresas concentradas geograficamente em polos moveleiros (ABDI, 2008). Observa-se que a concentração geográfica dessas empresas atrai uma diversidade industrial complementar à indústria moveleira, bem como viabiliza várias entidades de apoio, exclusivas ou não ao setor, de natureza pública ou privada, que dão suporte direto ou indireto à atividade econômica dessas empresas.

Diversas motivações de ordem teórica e prática fundamentam o esforço de pesquisa empenhado para este estudo. Tais motivações estão estreitamente inter-relacionadas, sobretudo pelo forte apelo de demandas gerenciais vinculadas às atuais fronteiras teóricas da área de Gestão de Cadeia de Suprimentos (GCS). Na medida em que os relacionamentos interorganizacionais são abordados simultaneamente em suas dimensões vertical e horizontal, ampliam-se as possibilidades de explicação de fenômenos relativos à GCS (LAZZARINI et al., 2001). Nesse aspecto, o contexto dos polos moveleiros é particularmente relevante como campo empírico.

Algumas características das pequenas empresas, como processos decisórios mais simples e maior proximidade entre nível organizacional e nível operacional, tendem a favorecer a integração entre elas. Contudo, outras características, como maior foco na eficácia em detrimento da eficiência, tendência à subutilização de tecnologias de informação e planejamento de curto prazo, constituem aspectos desfavoráveis à integração (GÉLINAS; BIGRAS, 2004).

\section{REDES DE RELACIONAMENTOS INTERORGANIZACIO- NAIS COMO ESTRATÉGIA DE CONCORRÊNCIA}

Dyer e Singh (1998) contribuíram decisivamente com as discussões no campo da estratégia, especialmente, ao redirecionarem as questões em torno das fontes de vantagem competitiva. A contribuição dos autores foi, tendo em vista que o foco dos estudos da estratégia consiste em explicar as diferenças de desempenho das firmas, sinalizar o papel dos relacionamentos e, em consequência, elaborar uma proposição teórica, identificada como visão relacional, que considera as díades e redes de firmas como unidade-chave de análise para explicar a performance superior das firmas.

Considerando-se suas bases e seus pressupostos, a visão relacional, de certo modo, pode ser considerada uma derivação da teoria baseada nos recursos (ACEDO; BARROSO; GALAN, 2006; PAULRAJ; LADO; CHEN, 2008). Pode-se entender esta forte relação especialmente pelo fato de a capacidade e as possibilidades de criação de valor estarem cada vez mais dependentes não apenas dos próprios recursos da organização, mas também daqueles de seus parceiros (CHADDAD, 2005).

Com o pressuposto de que a geração de vantagem competitiva pode estar além dos limites da firma, Dyer e Singh (1998) identificam quatro potenciais fontes de vantagens interorganizacionais: ativos específicos de relacionamento; rotinas de compartilhamento de conhecimentos; recursos e competências complementares; e governança efetiva. Desse modo, os ganhos relacionais são possíveis quando parceiros, em aliança, combinam, trocam ou investem em ativos idiossincráticos, conhecimento e recursos ou capacidades e/ou empregam mecanismos efetivos 
de governança que reduzem os custos de transação ou permitem a realização de ganhos por meio de sinergias na combinação de ativos, conhecimento ou competências (DYER; SINGH, 1998).

Tratando-se de relacionamentos, o elemento confiança destaca-se por seu papel na geração de valor. Conforme pontuam Pirani e Cunha (2010), o conceito de confiança é multidisciplinar, pois é de interesse de diferentes campos de estudos, como a psicologia, a economia, a sociologia e, mais recentemente, a administração.

Conceitualmente, confiança é um fenômeno que acontece no plano do indivíduo (DYER; CHU, 2003). Ou seja, ser confiável é um atributo possível às organizações, mas que acontece com base na ação do indivíduo. Os achados de Dyer e Chu (2003) apontam para a possibilidade de criação de valor por meio da confiança, gerando menores custos de transação. Os autores também argumentam que, enquanto mecanismos de governança, além de reduzirem os custos de transação, a confiança e o compartilhamento de informações se reforçam mutuamente, o que, por sua vez, gera valor nos relacionamentos de troca.

Nesse contexto, as empresas têm, de fato, buscado se apropriarem destes diferenciais por meio da formação de redes - as chamadas cadeias de suprimentos, o que representa uma mudança de paradigma na gestão de negócios, uma vez que as empresas já não competem como entidades autônomas, e sim entre cadeias de suprimentos (CHEN; PAULRAJ, 2004). Este é um paradigma de gestão que considera, fundamentalmente, que a coordenação da integração dos processos de negócios entre organizações seja orientada para o cliente final (COOPER et al., 1997).

A atenção ao relacionamento interorganizacional no contexto da cadeia de suprimentos tem sido apontada como fator primordial no processo de geração de valor tanto para o cliente final quanto para os diversos membros de uma cadeia. Nesse mesmo sentido, Simatupang e Sridharan (2001) definem a gestão da cadeia de suprimentos como uma estratégia colaborativa orientada para a geração de valor.

$O$ conceito de cadeia de suprimentos remete à estrutura de integração entre diferentes organizações, ao passo que o conceito de GCS remete ao processo e ao esforço de coordenação orientado para a criação de valor. Nessa direção, Mentzer et al. (2001) argumentam que uma cadeia de suprimentos e seu gerenciamento podem ser definidos pela integração de pelo menos três empresas que compartilham informações, prêmios e riscos, que cooperam, que integram processos, que têm metas e focos comuns, que formam parcerias de longo prazo, que reconhecem uma liderança e que aceitam uma estrutura de coordenação.

As cadeias de suprimentos e sua gestão são um campo em franco processo de sedimentação acadêmica, seja em seus aspectos de delimitação conceitual, seja nas possibilidades de operacionalização no âmbito gerencial (CHEN; PAULRAJ, 2003; MIGUEL; BRITO, 2009). Delimitando a GCS em um contexto de proximidade com a logística, Ballou (2004) argumenta que é muito difícil, em termos práticos, separar a logística integrada do gerenciamento da cadeia de suprimentos. De acordo com este autor, há uma semelhança na missão de ambas, que é: "colocar os produtos ou serviços certos no lugar certo, no momento certo e nas condições desejadas, dando, ao mesmo tempo, a melhor contribuição possível para a empresa" (BALLOU, 2004, p. 28). É neste contexto de integração conceitual que Ballou (2004) discorre sobre as diversas atividades da logística e seu papel na criação de valor para os clientes, fornecedores e outros interessados diretos.

Christopher (2005, p. 4) define o gerenciamento da cadeia de suprimentos como "a gestão das relações a montante e a jusante com fornecedores e clientes, para entregar mais valor ao cliente, a um custo menor para a cadeia de suprimentos como um todo". Considerando a ideia de uma cadeia estendida, a própria palavra "cadeia" passa a ter conotação de "rede", em função da existência de múltiplos fornecedores, fornecedores de fornecedores, múltiplos clientes e clientes 
de clientes, todos esses elementos presentes em um sistema total (CHRISTOPHER, 2005). Nessa direção, Christopher (2005, p. 5) destaca o conceito de cadeia de suprimentos como "uma rede de organizações conectadas e interdependentes, trabalhando conjuntamente, em regime de cooperação mútua, para controlar, gerenciar e aperfeiçoar o fluxo de matérias-primas e informação dos fornecedores para os clientes finais".

Ballou (2004) afirma que os benefícios da expansão das fronteiras organizacionais poderão ser de fácil identificação, mas de difícil operacionalização. Destaca, também, a importância central da coordenação, da colaboração e da confiança para a expansão das fronteiras organizacionais, bem como o papel do compartilhamento de informações crescente possibilitado pelo avanço de tecnologias e traduzido em coordenação, compromisso e cooperação (BALLOU, 2004).

Croxton et al. (2001) contribuíram substancialmente para a compreensão da GCS ao incorporarem a visão dos processos que permeiam a GCS nas dimensões estratégicas e operacionais. Esses autores identificaram oito categorias de processos de negócios que, sob o pressuposto do compartilhamento de informações, perpassam os diversos setores de uma organização, bem como os elos iniciais e finais na cadeia de suprimentos. Conforme Croxton et al. (2001), tais processos são: gestão de relacionamentos com clientes, gestão de relacionamentos com fornecedores, gestão de serviços para clientes, gestão de demanda, gestão de pedidos, gestão de fluxos da produção, desenvolvimento de produtos e comercialização e gestão de retornos.

O papel da GCS diz respeito à integração e ao gerenciamento destes diferentes processos ao longo de toda a cadeia de suprimentos (CROXTON et al., 2001). É a atenção a esse conjunto de processos que contempla os relacionamentos entre elos, permitindo o alinhamento da cadeia de suprimentos para a criação de valor.

\section{PROCEDIMENTOS METODOLÓGICOS}

A literatura classifica os relacionamentos em verticais, ou seja, os relacionamentos entre fornecedores, empresa focal e clientes (DYER, 1997, DYER; SINGH, 1998, ANDERSON; NARUS, 2003), e em horizontais, isto é, entre empresas que ocupam uma mesma posição dentro da cadeia de suprimentos ou, ainda, entre empresas e instituições de apoio, fomento e desenvolvimento (PARKHE, 1993). Ambos são de interesse deste artigo.

\subsection{Delineamento da pesquisa e procedimentos gerais}

Esta é uma pesquisa explicativa, na medida em que se propõe a aprofundar a compreensão dos relacionamentos interorganizacionais e seus desdobramentos. Trata-se, também, de uma pesquisa qualitativa e quantitativa, desenvolvida por meio de estudo comparativo. Assim, para o estudo em profundidade dos polos moveleiros de Mirassol e Ubá, foram conduzidas entrevistas semiestruturadas, de modo a prover explicações e caracterização dos relacionamentos em particular e das redes em geral.

O tipo de corte utilizado foi o longitudinal com cortes transversais. Neste caso, o interesse da pesquisa está no desenvolvimento do fenômeno ao longo do tempo, mas com foco em alguns momentos históricos desse desenvolvimento ou em incidentes críticos que marcaram a história do fenômeno e que têm relevância no momento atual. Todavia, a coleta de dados foi realizada em um único momento no tempo (VIEIRA, 2004).

Ainda quanto à caracterização, nesta pesquisa, tomaram-se por nível de análise as empresas moveleiras componentes dos polos estudados. Os depoimentos, as opiniões e as informa- 
ções obtidas dos empresários ou dirigentes das empresas moveleiras foram considerados unidades de análise tanto para o nível de análise empresarial quanto para o nível de análise de polo. Para o nível de análise de polo, também foram consideradas como unidades os depoimentos, as opiniões e as informações colhidas junto a gerentes, ou equivalentes, em entidades de apoio pesquisadas nos polos moveleiros.

Sob a ótica da GCS, ao tomar como nível de análise as empresas, sem desprezar, no entanto, a análise dos polos, este trabalho se alinha ao que preconizam Mentzer et al. (2001), ao argumentarem sobre a importância do papel da GCS no aperfeiçoamento do desempenho em longo prazo, tanto das empresas isoladamente quanto da cadeia como um todo.

Comparações entre empresas e polos foram objetos de triangulação metodológica, na medida em que dados e informações obtidos das empresas foram complementados ou confrontados com aqueles acerca das entidades de apoio aos polos. A triangulação de dados e informações a partir de múltiplas fontes de evidência visa conferir maior confiabilidade aos resultados da pesquisa (TRIVIÑOS, 1987).

\subsection{Coleta e tratamento dos dados}

A cronologia da pesquisa de campo seguiu a seguinte ordem: entidades de apoio no polo de Ubá; entidades de apoio no polo de Mirassol; empresas no polo de Mirassol; e empresas no polo de Ubá. Intencionalmente, as entrevistas com as entidades de apoio antecederam as entrevistas nas empresas. A expectativa foi que os profissionais dessas entidades, na maioria dos casos de nível gerencial, contribuiriam para a constituição de um panorama contextual do polo, gerando, inclusive, direcionamentos ou ajustes no roteiro de entrevistas que, em seguida, seria aplicado aos empresários. De fato, a cronologia foi útil nesse sentido.

No caso das entidades de apoio, a técnica utilizada foi a amostragem do tipo bola de neve ou snowball sampling (MALHOTRA, 2001). O ponto de partida das entrevistas, em ambos os polos, foram os sindicatos das empresas moveleiras. Pressupôs-se que seriam estas as entidades mais representativas nos polos, em função da inserção e do papel que exercem nesses ambientes, inclusive por serem exclusivamente dedicadas às empresas do setor.

Em cada polo, foi solicitado ao primeiro entrevistado que indicasse quais seriam as entidades relevantes para a atuação e o desenvolvimento do polo e quem seriam as pessoas indicadas para as próximas entrevistas, com a finalidade de ampliar a contextualização e o histórico do polo. A partir de uma lista de entidades e respectivos representantes, procedeu-se, aleatoriamente e conforme disponibilidade de agenda, à realização de entrevistas com os representantes das demais entidades. Após, a lista de entidades apontada pelo primeiro entrevistado foi apresentada ao segundo, para que este tivesse a opção de manter, ampliar ou reduzir a lista anterior pelo critério de julgamento quanto à relevância das entidades até então listadas. O procedimento foi repetido até o ponto de saturação, levando à consolidação de um grupo de entidades consideradas relevantes para o polo.

A pesquisa de campo foi conduzida entre os meses de agosto e novembro de 2012 . Ao todo, as entrevistas foram realizadas em 53 unidades, sendo 40 empresas - 23 empresas em Mirassol e 17 em Ubá - e 13 entidades de apoio, totalizando aproximadamente 49 horas de entrevistas gravadas, as quais foram, posteriormente, transcritas, à exceção de dois casos que não foram computados nas gravações, pois tiveram a coleta de dados realizada por telefone, anotações e e-mails.

Parte da análise dos dados qualitativos foi realizada por meio de ferramentas do software Atlas.ti, versão 4.1. Esclarecem Walter e Bach $(2009$, p. 1) que "O software Atlas.ti consiste 
em uma ferramenta para a análise da dados qualitativos que pode facilitar o gerenciamento e a interpretação dos mesmos".

Já o software IBM SPSS Statistics for Windows, versão 20.0, foi utilizado para o tratamento dos dados quantitativos. Esse software é um pacote estatístico composto de diferentes módulos, usado em ciências humanas, sociais e biológicas.

Para efeito comparativo, foi utilizado, para conjuntos de dados quantitativos, o teste $T$, o qual permite aplicação em amostras pequenas, comparativamente ao teste $Z$, e serve para verificar se há diferença entre as médias de duas amostras (WEBSTER, 2006). A interpretação dos resultados do teste T por meio do software IBM SPSS indica como primeiro passo a definição da hipótese a ser avaliada por meio do teste Levene: se Sig for inferior a 0,05, avalia-se a hipótese nula; se for superior a 0,05, avalia-se a hipótese 1. Em seguida, verifica-se o valor de Sig (2 tailed) com a finalidade de aceitar ou rejeitar a hipótese definida para avaliação no passo anterior.

\section{ANÁLISE DOS RESULTADOS}

As relações intra e intercategorias de organizações que formam um polo moveleiro tendem a ser caracterizadas por assimetrias. Para a empresa no contexto do polo, a importância relativa de cada categoria pode ser considerada um dos fatores que afetam as características do relacionamento.

Conforme pode ser visto na Tabela 1, registra-se, para ambos os grupos, uma considerável assimetria na importância atribuída aos componentes do polo. As relações de orientação vertical (clientes e fornecedores) correspondem a mais de $80 \%$ da importância distribuída, dividindo-se o restante entre as relações horizontais (entidades de apoio e demais empresas moveleiras do polo). Ressalta-se, ainda, que as médias apontam assimetria ligeiramente mais acentuada em Mirassol. Na comparação entre os grupos, para as quatro medidas, observa-se que as médias apresentam diferença estatística significativa, conforme os resultados da aplicação do teste $\mathrm{T}$.

Tabela 1 - Medidas para importância relativa percebida para os componentes do polo.

\begin{tabular}{|c|c|c|c|c|c|c|c|c|c|}
\hline Variável & Polo* & Média & Moda & Med & Máx & Mín & $\begin{array}{l}\text { Desvio } \\
\text { Padrão } \\
\end{array}$ & Sig & $\begin{array}{l}\text { Teste } T \\
\text { Sig ( } 2 \text { tailed) }\end{array}$ \\
\hline \multirow{2}{*}{$\begin{array}{l}\text { Importância relativa - } \\
\text { clientes }\end{array}$} & $\mathrm{M}$ & 55,455 & 40 & 55 & 90 & 31 & 15,287 & .131 & .111 \\
\hline & U & 48,333 & 50 & 50 & 70 & 30 & 11,504 & & \\
\hline \multirow{2}{*}{$\begin{array}{l}\text { Importância relativa - } \\
\text { fornecedores }\end{array}$} & $M$ & 29,636 & 30 & 30 & 50 & 5 & 10,298 & .148 & .421 \\
\hline & $U$ & 31,944 & 30 & 30 & 50 & 20 & 6,890 & & \\
\hline \multirow{2}{*}{$\begin{array}{l}\text { Importância relativa - } \\
\text { entidades de apoio }\end{array}$} & $M$ & 9,046 & 10 & 10 & 25 & 0 & 6,168 & .303 & .316 \\
\hline & $U$ & 11,278 & 10 & 10 & 30 & 0 & 7,744 & & \\
\hline \multirow{2}{*}{$\begin{array}{l}\text { Importância relativa } \\
\text { - demais empresas mo- } \\
\text { veleiras do polo }\end{array}$} & $\mathrm{M}$ & 5,864 & 0 & 4 & 23 & 0 & 6,490 & .291 & .193 \\
\hline & $U$ & 8,444 & 10 & 10 & 20 & 0 & 5,638 & & \\
\hline
\end{tabular}

* Número de observações = 22 para Mirassol e 18 para Ubá.

Fonte: resultados da pesquisa.

Essa baixa importância relativa das relações horizontais pode estar associada a certo senso de imediatismo. Ou seja, trata-se de considerar que importante para a empresa, essencialmente, são os clientes e os fornecedores, de tal modo que entidades de apoio e demais empresas moveleiras são partes de um ambiente dado, inclusive porque, em regra, o setor moveleiro encontra-se distribuído em polos, com padrões mais ou menos semelhantes em diferentes partes do país.

Tais observações, em parte, respaldam o argumento da Agência Brasileira de Desenvolvimento Industrial (ABDI) (2008, p. 13) de que, 
Na quase totalidade dos casos, são empresas familiares, com limitados recursos gerenciais e financeiros, que apresentam grande dificuldade em construir e se apropriar das vantagens competitivas. Por isso, a necessidade de se estruturarem em polos moveleiros.

\subsection{As relações verticais nos polos moveleiros}

Há ou não alguma diferenciação no relacionamento da empresa com seus principais clientes em comparação aos clientes de modo geral? Esta questão se coloca no contexto de um grau variável de concentração de clientes que cada empresa apresenta e revela padrões e diferenças na atitude dos empresários quanto aos relacionamentos com seus clientes.

A Figura 1, exposta a seguir, reúne os fatores de caracterização do relacionamento, permitindo comparações. Para esta figura e para as demais, quando aplicável, convencionou-se que: i) os números entre parênteses indicam a quantidade de entrevistados, quando maior que um, que corroboraram o termo caracterizador; e ii) os termos estão dispostos em três faixas horizontais, sendo a superior indicadora de alta incidência, a intermediária indicadora de incidência média, e a inferior indicadora de baixa incidência dos termos. Ademais, vale observar que, em parte, os elementos que se colocam como caracterizadores que distinguem Mirassol e Ubá não necessariamente representam diferenças entre esses grupos, mas características complementares entre os mesmos.

Figura 1 - Fatores influenciadores no relacionamento com clientes

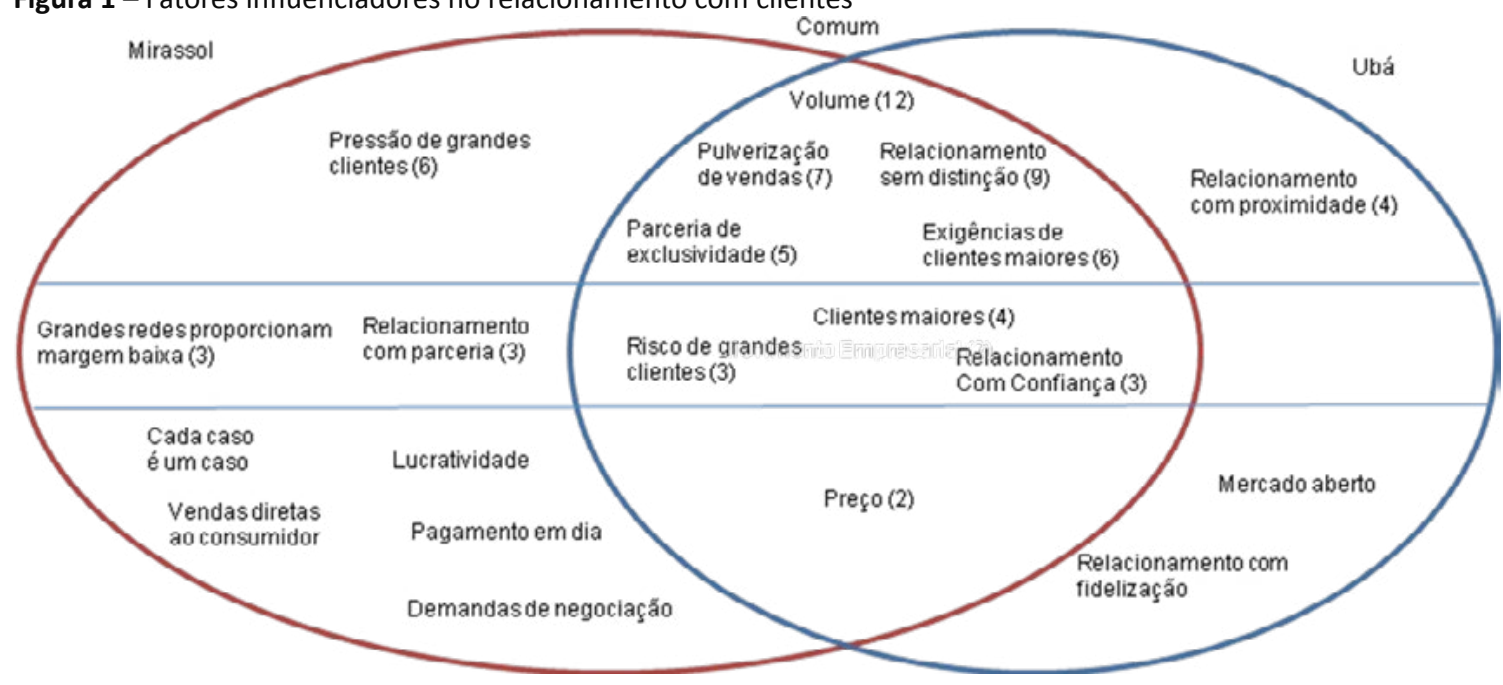

Fonte: resultados da pesquisa.

Em comum aos dois polos, nota-se que volume de vendas é o fator que mais se destaca, seguido dos argumentos, apontados por outros entrevistados, de que não há distinção no relacionamento e de que as vendas são pulverizadas. Registra-se, ainda, o fator exigências de clientes maiores, relativo a demandas principalmente observadas em relação a grandes redes de varejo, ou magazines, tanto que também aparece o registro clientes maiores, ligado a relacionamentos diferenciados e, ainda, o fator risco de grandes clientes, remetendo a baixas margens de lucratividade e problemas com assistência técnica, entre outros aspectos. Algumas empresas têm adotado diferenciação no relacionamento em parcerias de exclusividade de produtos e primado pelo fator relacionamento com confiança, ao passo que outras organizações optam por diferenciar o relacionamento pelo fator preço. 
Especificamente no caso de Mirassol, registra-se o fator pressão de grandes clientes, bem como o fato de as grandes redes proporcionarem margem baixa de lucratividade. Há, também, o fator parceria de exclusividade como orientador de relacionamentos diferenciados. Registra-se, ainda, a ideia expressa pelo fator cada caso é um caso. Ou seja, a diferenciação no relacionamento varia de empresa para empresa. Por fim, outros fatores que aparecem são: lucratividade, vendas diretas ao consumidor, pagamento em dia e demandas de negociação.

Em Ubá, ganha destaque a ideia de proximidade como parâmetro para relacionamentos diferenciados. Seriam casos que envolvem, por exemplo, amizade e laços de parentesco. Fala-se, também, do relacionamento com fidelização e, por outra via, de mercado aberto.

Quanto aos relacionamentos com fornecedores, a questão colocada é: há ou não diferenciação no relacionamento da empresa com seus principais fornecedores em comparação aos fornecedores de modo geral? Este questionamento segue a mesma lógica expressa no tópico anterior. De forma semelhante, o contexto é de variação na concentração de fornecedores. Todavia, observou-se que, para determinados tipos de matéria-prima, existem poucos fornecedores disponíveis.

A Figura 2 reúne, comparativamente, os fatores de caracterização para os relacionamentos das empresas com seus fornecedores.

Figura 2 - Fatores influenciadores no relacionamento com fornecedores

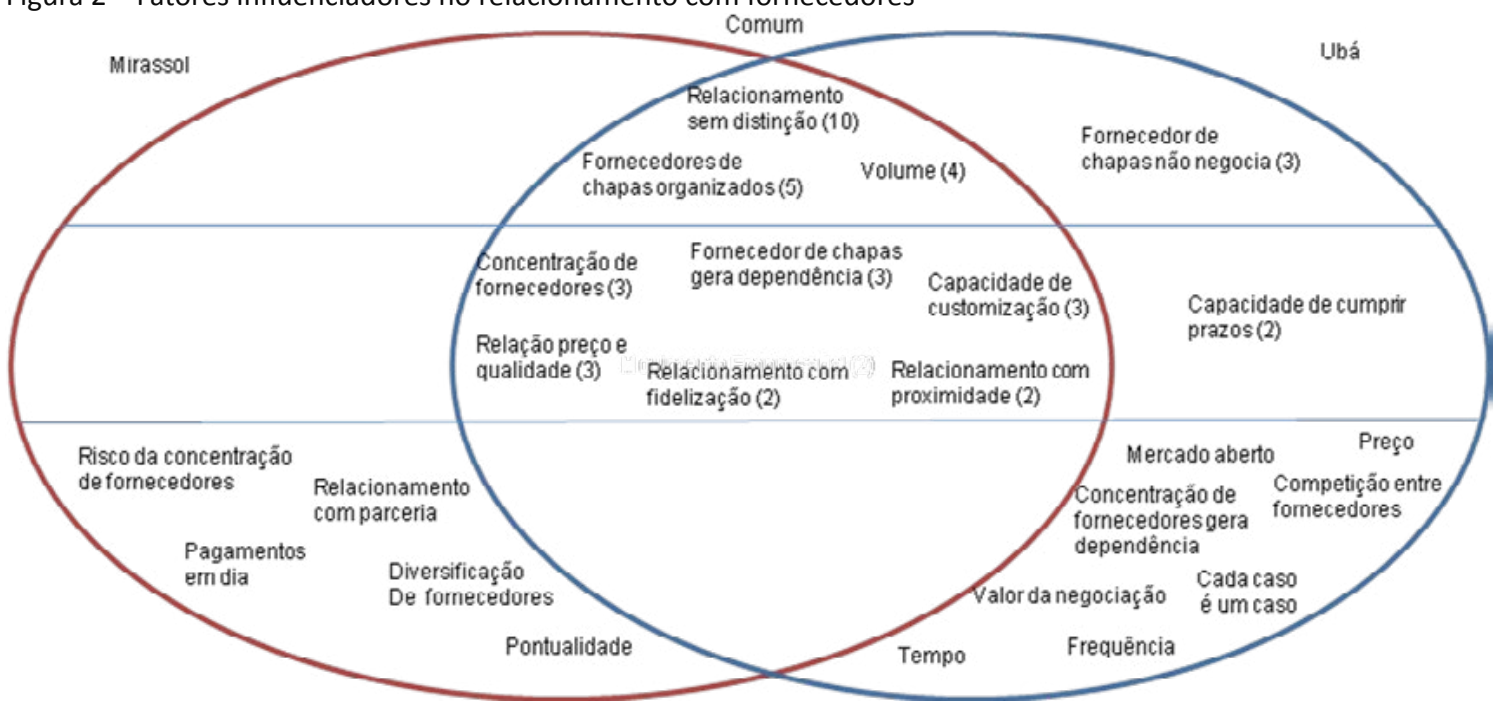

Fonte: resultados da pesquisa.

Comum a ambos os polos, destaca-se o fator relacionamento sem distinção, ou seja, o argumento de que não existe nenhuma diferenciação no relacionamento com um ou mais fornecedores. Os entrevistados destacaram um tipo específico de fornecedor, o de chapas de madeira, argumentando que são organizados e que geram dependência na relação com as empresas moveleiras, que há uma concentração de fornecedores das principais matérias-primas, que o volume é fator de diferenciação e que existe a relação preço e qualidade. Também apareceram os fatores capacidade de customização, fidelização e proximidade como parâmetros para relacionamentos diferenciados.

As empresas de pequeno porte indicaram ser mais relevantes os relacionamentos horizontais, isto é, aqueles com clientes e fornecedores, do que aqueles com entidades de apoio e outras empresas do polo (relacionamentos horizontais). Esta situação poderia ser interpretada como a presença nas empresas de um perfil que prioriza a sua participação nas cadeias de suprimentos e minimiza sua posição em um Polo Industrial ou Arranjo Produtivo Local (APL), enten- 
dendo que as cadeias de suprimentos possibilitam sua sustentabilidade.

No entanto, na análise das prioridades do formato dos relacionamentos com clientes e fornecedores, fica evidenciada a falta de estratégia de gestão destes relacionamentos, principalmente no que diz respeito à pouca importância destinada às ações colaborativas - relacionamento com colaboração, relacionamento com proximidade e relacionamento com fidelização. Isso distancia estas empresas de absorverem os benefícios potenciais da inserção em cadeias de suprimentos, fato que pressupõe integração e colaboração. Por meio da cooperação e da colaboração, as empresas conseguem melhorias em relação à sua atuação isolada (Amato Neto, 2000), o que favorece a construção de mecanismos de capital social, como a confiança e a solidariedade.

Martins (2013) já havia constatado que não ocorrem, de forma generalizada, práticas colaborativas nas operações de PMEs localizadas em APLs. Em suma, em termos das operações, não são aplicados os princípios gerais de integração e de colaboração. Isso significa que as empresas dos APLs deixam de aproveitar os benefícios que uma estratégia conjunta poderia proporcionar, benefícios estes ligados à redução do custo logístico, à melhoria no nível de serviço recebido e à melhoria no nível de serviço oferecido aos clientes finais.

Ademais, conforme Martins et al. (2013), a imersão relacional e estrutural é um mecanismo complementar de governança, em que uma organização depende da outra para a obtenção de ganhos. A imersão relacional possui uma perspectiva de coesão na rede e ressalta o papel dos laços e da confiança no acesso à informação. Já a imersão estrutural tem uma perspectiva posicional e pode ser medida pelo nível de concentração de compras, no caso de fornecedores, e de vendas, no caso de clientes.

\subsection{As relações horizontais nos polos moveleiros}

\subsubsection{Entidades de apoio no polo}

A comparação entre os conjuntos consolidados de entidades de apoio mostra que os polos se assemelham quanto ao grupo das mais relevantes. No polo de Mirassol, o conjunto consolidado foi de apenas quatro entidades, contra nove em Ubá. No entanto, dentre as de Ubá, as quatro mais importantes, na visão dos representantes das entidades, correspondem exatamente ao conjunto observado em Mirassol (Gráfico 1).

Gráfico 1 - Importância relativa de entidades de apoio nos polos de Mirassol e em Ubá

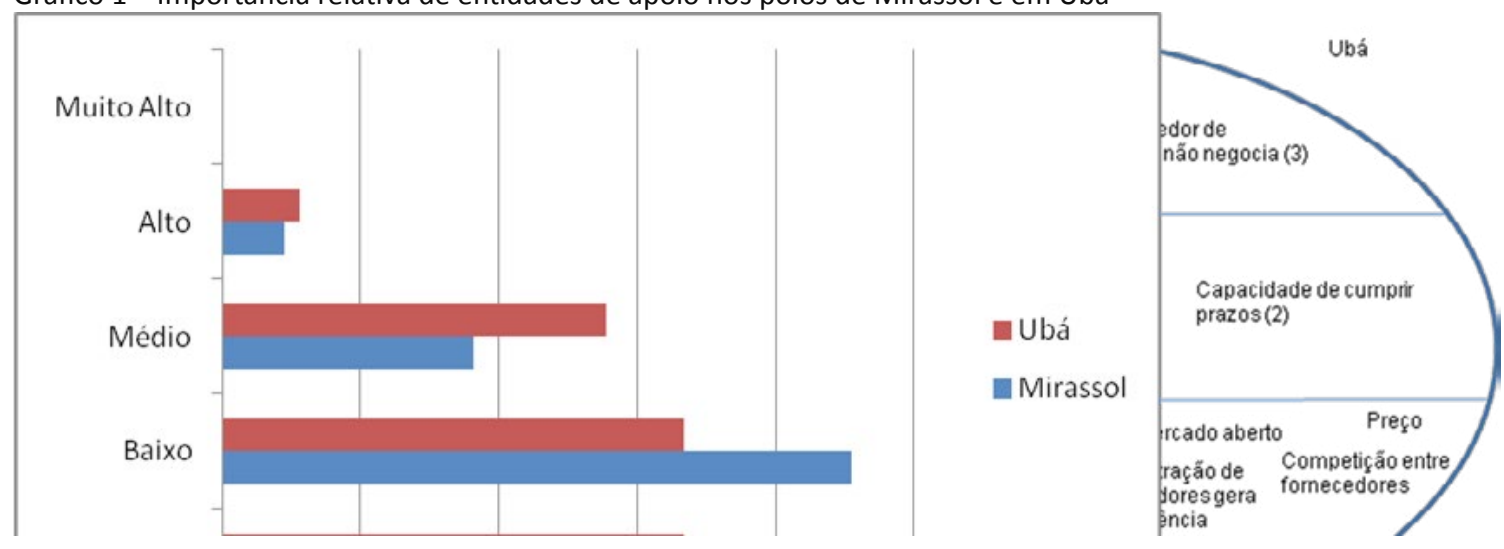

Fonte: resultados da pesquisa. 
Nos dois polos pesquisados, os sindicatos das empresas moveleiras figuram como a principal entidade de apoio, sob a perspectiva tanto dos representantes das próprias entidades quanto dos empresários. Em resposta a outro questionamento desta pesquisa, o sindicato foi largamente reconhecido como a entidade que promove a governança nos dois polos.

Ao analisar o escore atribuído ao sindicato e ajustar os escores das demais entidades, comparando os valores atribuídos pelas entidades e pelas empresas, observa-se um descompasso entre a percepção dos empresários e a percepção dos representantes das entidades de apoio. A exceção é o que se observa no caso do Serviço Nacional da Indústria (SENAI) no polo de Ubá, caso em que se registrou situação inversa. Ficou evidenciada, nas entrevistas com os empresários, a valorização do papel da referida entidade no quesito formação de mão de obra qualificada para as empresas moveleiras, em especial por meio de programas como "Menor Aprendiz", em um contexto em que afloraram nas entrevistas, em ambos os polos, a disponibilidade e a qualidade da mão de obra como fator crítico para o setor.

Se, de um lado, registram-se em Ubá infraestrutura e atuação estabelecida, no polo de Mirassol, diferentemente, o SENAI foi a entidade que recebeu menor escore, pelo olhar tanto dos representantes das entidades quanto dos empresários. Entretanto, há uma probabilidade de que tal cenário se modifique nos próximos anos em função de investimentos em infraestrutura que estão sendo realizados pelo SENAI em Mirassol.

Outro destaque para o polo de Ubá é a diferença entre os escores das universidades e da agência de desenvolvimento do município. No caso das universidades, percebe-se que, enquanto as demais entidades reconhecem tais instituições como provedoras de conhecimentos e inovações, as empresas observam-nas pela via do distanciamento e da falta de pragmatismo. De fato, foi recorrente nas entrevistas a reclamação dos empresários sobre empecilhos para maior aproximação entre universidades e empresas, incluindo desde questões burocráticas até a falta de acesso a resultados de pesquisas realizadas nas próprias empresas. No caso da agência de desenvolvimento, pesa a diferença no reconhecimento do papel institucional para o polo.

O motivo de instituições financeiras (bancos) figurarem na quinta e na sexta posição, tal como destacado pelos empresários no polo de Ubá, e de não aparecerem no polo de Mirassol chama a atenção, uma vez que tais instituições tendem a ser semelhantes em termos de produtos e serviços financeiros, direcionados ou não para a indústria moveleira em ambos os polos.

Foram identificados fatores ligados a características da governança e a problemas de governança. Quanto a características, para os dois polos, destacam-se: Sindicato (17) e tentativa do Sindicato (7), surgindo também a ideia de que a governança acontece por uma articulação entre o Sindicato e o Serviço Brasileiro de Apoio às Micro e Pequenas Empresas (SEBRAE) (5). É possível distinguir, ademais, alguns problemas de governança. Nesse sentido, aparecem em comum: baixa adesão dos empresários às ações do Sindicato (5), falta de comprometimento dos empresários (3), diferenças entre grandes e pequenas empresas como inibidor de uma coordenação efetiva (3) e a ideia de que falta insistência por parte do Sindicato (2).

É claramente perceptível a carência de um sistema de governança mais efetivo nos polos que influencie a troca de informações e de recursos e a complementação entre as empresas, permitindo a geração de valor relacional (DYER; SINGH, 1998). Sob uma perspectiva racional, a estrutura de governança em redes de empresas é resultante do processo de negociação entre os participantes do arranjo. Cada empresa renuncia a determinadas liberdades individuais em prol de uma coordenação do coletivo, sob um regime de regras que regem o grupo (WEGNER, 2011; ALBERS, 2005). Diferenças culturais, de porte e de fragilidade no capital social, por exemplo, têm forte poder de explicação acerca da fragilidade da sinergia evidenciada nos polos. 


\subsubsection{Relacionamentos com demais empresas moveleiras do polo}

A atribuição de intensidade ao relacionamento entre as empresas nos polos em escala variando de "Muito baixo" a "Muito alto" revelou um relacionamento interorganizacional fraco nos polos, ligeiramente mais acentuado no de Ubá (Gráfico 2). Vale registrar que, além da ausência de atribuição de nota "Muito alto", nos casos em que se atribuiu nota "Alto", os entrevistados relataram ações colaborativas que não diferiam essencialmente das citadas por aqueles que atribuíram notas inferiores para o relacionamento entre as empresas.

Gráfico 2 - Intensidade do relacionamento entre empresas moveleiras no polo

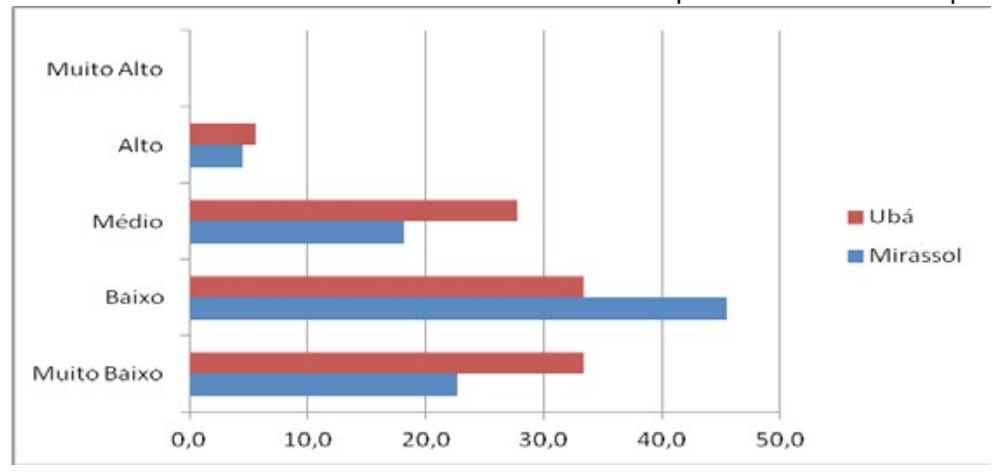

Fonte: resultados da pesquisa.

Diante da escassez de experiências de investimentos em ativos específicos de relacionamento, para esta categoria, preferiu-se o termo ações conjuntas por ser mais abrangente quanto ao empenho em esforços coletivos nos polos. Em comum aos dois polos, a categoria ações conjuntas foi utilizada para expressar os ativos específicos de relacionamento. Neste caso, houve destaque para a ideia de que as empresas tendem a agir isoladamente (20) e de que não há ações conjuntas (5).

Muitas vezes, foi citada uma barreira para ações conjuntas advinda do porte diferenciado entre as empresas. De acordo com Bleeke e Ernst (2001), as parcerias tendem a obter melhores resultados quanto menos desiguais forem os parceiros. Este pode ser um fator associado aos relacionamentos em pequenos grupos e com tendência a acontecer entre empresas de portes semeIhantes, conforme observado principalmente no polo de Ubá. Entretanto, a heterogeneidade dos parceiros também oferece benefícios se considerada, por exemplo, a perspectiva do capital social, conforme Burt (2001), na medida em que o acesso a recursos e informações se torna redundante.

Por outro lado, o fenômeno das ações em pequenos grupos de empresas moveleiras pode ser observado à luz de explicações teóricas sobre a ação coletiva, fornecidas por Olson (1999). Este autor explica que organizações são criadas por grupos de indivíduos em prol de objetivos coletivos, de modo que os bens coletivos gerados beneficiam a todos e podem ser consumidos por todos. No caso dos dois polos estudados, observou-se que apenas cerca de um terço das empresas moveleiras é filiado ao sindicato no polo.

Na categoria compartilhamento de informação, destacam-se, em comum a ambos os polos, os termos baixo compartilhamento de informação (13), não há compartilhamento de informação (4), compartilhamento de informação em pequenos grupos (6), compartilhamento de informação sobre transporte (2) e compartilhamento de informação entre concorrentes não diretos (2). Já na categoria complementação, em comum aos dois polos, aparece o termo terceirização de acessórios (4), referindo-se aos complementos de produtos (kits de ferragens, pés de móveis e outros). 
É característico também o fato de que a terceirização tende a preservar as relações no contexto de laços sociais, o que pode estar associado ao medo de que a prática desenvolva possíveis competidores. No polo de Ubá, a terceirização, que também se revela como forma de complementação entre empresas, apesar de crescente, é apontada como pouco incidente no polo. Ademais, a terceirização acontece por necessidade, uma vez que se admite a inviabilidade de internalizar determinados processos e que, mesmo assim, a terceirização é considerada, ainda, como um acontecimento coordenado pelas empresas maiores.

As evidências sugerem, assim, insuficiência de elementos empíricos de cadeia de suprimentos no polo, tanto pela ausência de cooperação e integração de processos (MENTZER et al., 2001) quanto pela ausência de uma estratégia colaborativa para a geração de valor (SIMATUPANG; SRIDHARAN, 2001).

\subsection{As formas dos relacionamentos e seus impactos para as empresas}

O desafio de projetar e gerenciar uma rede de relações interdependentes, tal como argumentado por Chen e Paulraj (2004), manifesta-se com elevada intensidade nos dois polos moveleiros pesquisados. $O$ contexto de polos industriais (aglomerações geográficas) propicia a simultaneidade da colaboração e da competição entre empresas enquanto estas competem no mercado (MCEVILY; ZAHEER, 2004). A proximidade geográfica tende a propiciar sobreposições de relações entre empresários, a demandar a formação, ou ações, de entidades de apoio e a atrair investimentos e políticas públicas voltados ao setor, mas não implica, necessariamente, a propensão a relacionamentos colaborativos entre as empresas.

A cooperação e a competição, consideradas como dinâmica da evolução tecnológica nesses polos, ajustam-se à dicotomia exploration e exploitation, apresentada por March (1991), referindo-se ao trade-off entre utilização e exploração de novos conhecimentos ou recursos. Determinados padrões característicos das empresas moveleiras são moldados por força de evoluções tecnológicas na indústria, especialmente em casos que representam alterações nos padrões competitivos. Como já citado, historicamente, exemplos disso seriam a inserção de Medium Density Fiberboard (MDF) na fabricação de móveis e a tecnologia de pintura ultravioleta. Nesses casos, a resistência é vencida por força da necessidade de sobrevivência das empresas. Então, passa-se a novos parâmetros de competitividade, sobretudo em função de incremento na produtividade. Quando tais mudanças acontecem, as empresas que não se atualizam tendem a não sobreviver, fato que explica uma onda de falência de empresas no polo de Mirassol por volta de 2000.

Identificaram-se, então, três possíveis situações nas quais se encontram relacionamentos interorganizacionais mais intensos: a) épocas de crise econômica com impactos negativos para o setor; b) projetos de maior envergadura, promovidos, em regra, por entidades de apoio e ligados a políticas públicas; e c) pequenos grupos com laços de parentesco ou de amizade, formados por empresas que não são concorrentes diretos. No primeiro caso, pesam a necessidade de sobrevivência e a inviabilidade de a empresa, isoladamente, contornar determinada situação. Já no segundo caso, independente do momento de crise, a adesão orienta-se pela objetividade na perspectiva de retornos. O terceiro caso, por sua vez, diferencia-se pela possibilidade de longevidade nas relações. Ainda que os membros não estejam livres do risco de comportamento oportunista, os mecanismos de governança e de ajustes são mais efetivos nestas relações.

À medida que cresce a escala de produção e que os produtos se diferenciam por aspectos como cores, desenhos e estilos, há a tendência de que uma mesma empresa produza um portfólio diversificado de produtos. Esse fenômeno faz com que várias empresas concorram 
com produtos semelhantes, o que amplia o risco de possíveis imitações e de concorrência pelos mesmos mercados. Assim, são minadas eventuais vantagens de algumas empresas, e, ao mesmo tempo, gera-se resistência à colaboração pela complementaridade na comercialização, o que seria um possível caminho para fortalecimento perante fornecedores e clientes, por exemplo.

Quanto às entidades de apoio, apesar de serem indutoras de ações colaborativas, há dificuldades para sua inserção nos polos, não atingindo a diversidade de demandas, além da dificuldade de articulação de programas de longo prazo e de maior alcance em termos de ações coletivas. Na medida em que as ações são isoladas, as organizações não propiciam desenvolvimento de confiança e não conseguem passar a ações mais abrangentes. Em certa medida, são reproduzidas, na ação das entidades de apoio, as dificuldades para transitar da lógica transacional para a lógica relacional.

Há uma resistência ao relacionamento colaborativo entre as empresas: a colaboração é restrita a pequenos grupos no interior do polo, sobretudo àqueles que têm vínculos de maior proximidade (parentesco e amizades) e que não são concorrentes diretos em termos de produtos similares. Para estes casos, ações colaborativas ocorrem mesmo sem a intervenção de entidades de apoio.

A clara preocupação com os concorrentes diretos no interior de cada polo reflete o individualismo e denota a ausência de coordenação em termos de definição de mercados. Em outras palavras, reflete a predominância de atenção em curto prazo a um ambiente de negócios mais próximo (GÉLIDAS; BIGRAS, 2004).

A partir dos resultados da pesquisa, notam-se problemas de coordenação e de governança no polo. Em Mirassol, fala-se da necessidade de "afinar como uma orquestra" para que o relacionamento colaborativo tenha expressão. Em Ubá, fala-se que "um culpa o outro e não relaciona", pois o que se enxerga são concorrentes, e não parceiros. Uma peculiaridade relevante a esse respeito é que, em contexto de crise, ocorre aproximação entre os empresários. Apesar dos problemas de coordenação, os sindicatos e outras entidades de maior inserção têm atuado no sentido de facilitar ou promover condições para intensificar os relacionamentos.

McEvily e Zaheer (2004) entendem que ações deliberadas, envolvendo interesses compartilhados, expectativas comuns, formação de uma "massa crítica de influência" e adensamento da rede, atuam como criadoras de confiança entre os elos da rede. Os autores lembram que a confiança não deve ser tratada como puramente diádica, já que, entre um comprador e um vendedor, por exemplo, há um contexto e um ambiente no qual se desenvolve a confiança.

De fato, há padrões de critérios semelhantes sobre escolhas de parceiros nos negócios e sobre fatores ligados a enfraquecimento ou encerramento de relacionamentos comerciais. $\mathrm{Na}$ caracterização dos relacionamentos verticais (fornecedor-empresa-cliente), tipicamente definidores da cadeia de suprimentos, ganham destaque a baixa orientação para relacionamentos colaborativos na relação com fornecedores e a assimetria no poder de barganha para alguns tipos de suprimentos essenciais à atividade moveleira. Cenário semelhante pode ser percebido na relação com os clientes, pois, apesar da pulverização de vendas, a atenção está voltada para negociações em volume ou para a não distinção nas formas de relacionar.

Em grande medida, o cenário descrito nesses polos tem sido o de que a empresa moveleira está pressionada pela concentração de fornecedores, de um lado, e pelo poder de barganha de grandes redes varejistas, de outro, fenômeno que tem acentuado a pressão sobre as margens de ganho no setor, ainda que uma parcela das empresas escape diretamente desse molde. Notou-se que parte das empresas utiliza práticas para minimizar os riscos associados à concentração de clientes, notadamente por meio de definições de políticas quanto a limites percentuais aceitos em termos de concentração de clientes. 
À exceção de alguns casos, tomando como referência os grupos de empresas pesquisadas, não há elementos empíricos claramente definidores de cadeia de suprimentos, como exposto no referencial teórico, orientados à geração de valor e com foco no cliente final. A ressalva são algumas empresas que vêm desenvolvendo elementos caracterizadores de cadeias de suprimentos com clientes, fornecedores e, até, empresas terceirizadas, mas são poucas experiências em relação ao número total de empresas nesses polos.

O fortalecimento das relações verticais no contexto dos polos estudados é, em parte, dependente das relações horizontais que ali acontecem. Entretanto, em muitos casos, as ações colaborativas induzidas, ainda que em horizontes de médio prazo, articuladas em projetos como o APL (programa ligado à política pública do governo federal com finalidade de melhorar a competitividade em APLs em diversas regiões no Brasil), têm adesão limitada no tempo, funcionam sob certas condições e demandam esforço de convencimento e de insistência para que ocorram.

Ademais, a adesão a essas ações coletivas tem sido norteada sob uma perspectiva clara de retorno imediato. A lógica transacional nas relações suplanta os esforços de implementação da lógica relacional, uma vez que as ações cotidianas de iniciativa dos empresários e, mesmo, aquelas de iniciativa das entidades de apoio reforçam a lógica transacional.

Considerando as características constitutivas dos componentes dos polos, o modo como os relacionamentos são conduzidos e o que se identificou como vantagens e desvantagens, não é possível constatar relacionamentos colaborativos duradouros gerando vantagem competitiva nesses polos, em que pese a existência de oportunidades que a estrutura vertical versus horizontal poderia gerar para ocasionar mudanças nesses cenários.

A criação de valor ou os resultados que advêm dos relacionamentos podem ser diretos ou indiretos. Como resultados diretos, citam-se a expansão dos lucros, o incremento nos volumes de transações e a promoção de salvaguardas. Como resultados indiretos, têm-se: oportunidades de inovação, acesso a novos mercados e informações sobre eles e acesso a organizações estrategicamente relevantes (WALTER et al., 2001).

$\mathrm{O}$ individualismo e as características culturais figuram como importantes motivos pelos quais as empresas estudadas não se relacionam e, ao mesmo tempo, sinalizam resistência relativamente forte para mudança. De tal modo, a lógica transacional, além de sobrepujar a lógica relacional nos polos, aponta para o fato de que as relações entre essas duas lógicas não são facilmente transitáveis.

Adicionalmente, a confiança, enquanto elemento essencial para a manutenção de relacionamentos, caracteriza-se também como fenômeno autogerativo. Tanto a confiança quanto a desconfiança tendem a ser reforçadas, respectivamente, pelas experiências positivas ou negativas a elas associadas.

A forma de operacionalização do trabalho conjunto implica comprometimento e monitoramento das relações. Elementos como coordenação, colaboração e confiança são centrais à GCS (BALLOU, 2004). A confiança pode ser reduzida ou inibida mediante a ausência de compartilhamento de informações. Portanto, este fator influencia tanto o desenvolvimento quanto a manutenção das relações em cadeias de suprimento (FARIA et al., 2010; HANDFIELD et al., 2000).

\section{CONSIDERAÇÕES FINAIS}

Esta pesquisa procurou contribuir para a compreensão de como se configuram os relacionamentos horizontais e verticais de PMEs e quais seus desdobramentos para estas empresas quanto à sua inserção em cadeias de suprimentos. Para tanto, foram utilizadas experiências de empresas moveleiras localizadas em polos industriais. 
Esta pesquisa revelou fatores ligados mais ao não desenvolvimento dos relacionamentos do que ao seu desenvolvimento e à sua manutenção. Ademais, considerando-se a particularidade da concentração geográfica das empresas pesquisadas, os fatores que condicionam as relações, sejam elas horizontais ou verticais, são da mesma natureza. Assim sendo, o fortalecimento das relações verticais é, em parte, dependente das relações horizontais que acontecem nos polos.

Percebeu-se, também, que as relações horizontais são pouco valorizadas em comparação às relações verticais. Essa assimetria restringe o poder de influência das entidades de apoio e das relações entre as empresas diante dos relacionamentos dessas empresas com seus clientes e fornecedores. Agindo desta forma, as empresas não criam forças para suas próprias reivindicações, especialmente frente a governos e órgãos públicos no que diz respeito ao delineamento de políticas públicas e ações conjuntas. Ademais, as empresas que se relacionam por necessidade ou por uma perspectiva clara de ganhos com baixo risco têm aversão a relações com empresas com produtos ou mercados semelhantes.

Nas relações verticais, tanto para fornecedores quanto para clientes, ganha destaque a ausência de estratégia de relacionamentos. Além disso, as empresas são pressionadas pelos efeitos da concentração de fornecedores de determinados tipos de matéria-prima. Da mesma forma, em relação a seus clientes, também sofrem pressão das grandes redes varejistas. Escapam parcialmente a esses problemas de assimetrias algumas empresas que pulverizam suas vendas ou que buscam diferenciação em seus produtos visando atender nichos específicos de mercado.

Conclui-se, assim, que há um grande potencial no desenvolvimento de relacionamentos de cunho colaborativos para fins de saltos competitivos e inserção mais adequada das PMEs em cadeias de suprimentos. Algumas oportunidades podem ser criadas entre as próprias empresas, com o desenvolvimento de atributos como confiança e competência técnica que levem à complementaridade. PMEs poderiam, por exemplo, atuar como fornecedores de partes ou componentes de produtos para empresas de maior porte, mas acabam sendo seus concorrentes em termos de produtos finais em condições desfavoráveis.

As entidades de governança são esvaziadas em sua função de indutoras de ações colaborativas, pois não atingem a diversidade de demandas. Há, ainda, uma dificuldade de articulação de programas de longo prazo e de maior alcance em termos de ações coletivas. Na medida em que as ações são isoladas, as organizações não propiciam desenvolvimento de confiança e não conseguem executar ações mais abrangentes. Em certa medida, reproduzem-se, na ação das entidades de apoio, as dificuldades para transitar da lógica transacional para a lógica relacional.

A resistência aos relacionamentos colaborativos entre as empresas, a baixa adesão a entidades de representação e o baixo nível de confiança, dentre outros elementos captados, definem os padrões de critérios para os relacionamentos não orientados à integração e geração de valor com foco no cliente final. Na formação de sua rede de relacionamentos verticais (fornecedor-empresacliente), ganha destaque a baixa orientação para relacionamentos colaborativos na relação com fornecedores e com os clientes, devido à declarada falta de distinção nas formas de se relacionar.

Em relação às limitações desta pesquisa e a recomendações para trabalhos futuros, salienta-se que um maior número de observações teria sido importante para que, por meio de técnicas estatísticas paramétricas, por exemplo, fossem demonstrados os pesos relativos de cada variável componente. A escolha dos dois polos moveleiros para a pesquisa empírica foi orientada pelo critério de figurarem entre os principais no Brasil. Todavia, o estudo contemplando os polos de Mirassol e de Ubá veio a revelar ambientes semelhantes, notavelmente caracterizados pela baixa intensidade de relacionamentos colaborativos.

Diante disso, recomendam-se estudos sobre o fenômeno dos relacionamentos inte- 
rorganizacionais em contextos de pequenos grupos, no que diz respeito a seus mecanismos de governança e de ajustes em suas relações. Seriam enriquecedoras, também, pesquisas que abordem como objeto central as entidades de apoio, bem como seus mecanismos de articulação e de concepção de suas ações. Do mesmo modo, estudos que avaliem as políticas públicas direcionadas a APLs seriam importantes. Por fim, destaca-se a relevância de pesquisas que produzam conteúdos teóricos sobre a área de operações, de GCS e de logística, abordando variáveis mais específicas ao contexto brasileiro, como, por exemplo, variáveis de ordem cultural.

\section{REFERENCIAS}

ABDI. Agência Brasileira de Desenvolvimento Industrial. Relatório de Acompanhamento Setorial - Indústria Moveleira. Campinas: ABDI-Unicamp, 2008.

ACEDO, F. J.; BARROSO, C.; GALAN, J. L. The Resource-based Theory: dissemination and main trends. Strategic Management Journal, v. 27, n. 7, p. 621-636, 2006.

ALBERS, S. Configurations of alliance governance Systems. Schmalenbach Business Review, n. 62, p. 204-233, 2010.

ANDERSON, J. C.; NARUS, J. A. Selective Pursuing Greater Share of the customer.s Business. ISBM Report-3-2003, p. 2-16, Mar. 2003.

AMATO NETO, J. Redes de cooperação produtiva e clusters regionais: oportunidades para as pequenas e médias empresas. São Paulo: Atlas, 2000.

BALLOU, R. H. Business Logistics: Supply Chain Management. 5. ed. New Jersey: PearsonPrentice Hall, 2004.

BANDEIRA-DE-MELLO, R.; CUNHA, C. J. C. de A. Operacionalizando o método da grounded theory nas pesquisas em estratégia: técnicas e procedimentos de análise com apoio do software Atlas/ti. In: Encontro de Estudos em Estratégia, 1, 2003, Curitiba. Anais... Rio de Janeiro: ANPAD, 2003.

BLEEKE, J.; ERNST, D. Colaborando para competir. In: MINTZBERG, H. \&QUINN, J. B. (Orgs.). $O$ processo da estratégia. Porto Alegre:
Bookman, 2001.

BURT, S.R. Structural holes versus network closure as social capital. In: LIN, N.; COOK, K.; BURT, S.R. (Eds.). Social capital: theory and research. New York: Aldine de Gruyter, 2001.

CHADDAD, F. R. Networking for Competitive Advantage: The case of cooperatives in the United States. IXXX Encontro da Associação Nacional de Pós-Graduação em Administração. Brasília, Anais..., Rio de Janeiro: ANPAD, 2005.

CHEN, I.; PAULRAJ, A. Towards a Theory of Supply Chain Management: The constructs and measurements. Journal of Operations Management, v. 22, p. 119-150, 2004.

CHRISTOPHER, M. Logistics \& Supply Chain Management: creating value-adding networks. 3. ed. London: FT Press, 2005.

COOPER, M.; LAMBERT, D. M.; PAGH, J. D. Supply Chain Management: More than a new name for logistics. International Journal of Logistics Management, v. 8, n. 1, 1997.

CROXTON, K. L. et al. The supply chain management process. The International Journal of Logistics Management, v. 12, n. 2, p. 13-36, 2001.

DYER, J. H. Effective Interfirm Collaboration: How firms minimize transaction costs and maximize transaction value. Strategic Management Journal, v. 18, n.7, 535-556, 1997

DYER, J. H.; CHU, W. The Role of Trustworthiness in Reducing Transaction Costs and Improving Performance: Empirical evidence from the United States, Japan, and Korea. Organization 
Science, v. 14, n. 1, 2003, p. 57-68.

DYER, J. H.; SINGH, H. The Relational View: Cooperative strategy and sources of interorganizational competitive advantage. Academy of Management Review, v. 23, n. 4, p. 660-679, 1998.

FARIA, A. C.; MACHADO, J. P. S.; ARRUDA, A. G. S. Compartilhamento de Informações em Cadeias de Suprimentos: Levantamento da produção científica nos EnANPADs de 2000 a 2009. XXXIV Encontro da Associação Nacional de Pós-Graduação e Pesquisa em Administração. Anais..., Rio de Janeiro, Brasil: 2010.

GÉLINAS, R.; BIGRAS, Y. The Characteristics and Features of SMEs: Favorable or unfavorable to logistics integration? Journal of Small Business Management, v. 42, n. 3, 2004.

HANDFIELD, R. et al. Avoid the Pitfalls in Supplier Development. Sloan Managment Review. Winter 2000. p. 37-49.

LAZZARINI, S. G.; CHADDAD, F. R.; COOK, M. L. Integrating Supply Chain and Network Analyses: The study of netchains. Chain and network Science. 2001.

MALHOTRA, N. Marketing Research: An applied orientation. Prentice Hall, New Jersey, 2001.

$\mathrm{MARCH}$, J. Exploration and Exploration in Organizational Learning. Organization Science, v. 2, n. 1, p. 71-87, 1991.

MARTINS, R. S. Colaboração nos processos logísticos de empresas pequeno e médio portes em arranjos produtivos. Revista da Micro e Pequena Empresa (FACCAMP), v. 7, p. 46-95, 2013.

MARTINS, G. S.; ROSSONI, L.; MARTINS, R. S.; DUARTE, A. L. C. M. O Relacionamento na Cadeia de Suprimentos e Seus Efeitos no Desempenho Operacional: Evidências do Setor Moveleiro Brasileiro. In: XXXVII Encontro da
ANPAD, 2013, Rio de Janeiro. Anais..., 2013.

MATTAR, F. N. Pesquisa de Marketing: Edição compacta. São Paulo: Atlas, 1996.

MDIC. MINISTÉRIO DO DESENVOLVIMENTO, INDÚSTRIA E COMÉRCIO EXTERIOR. Relatório sobre Fatores de Influência no Desenvolvimento Tecnológico e Inovação nas microempresas e empresas de pequeno porte. Secretaria do Desenvolvimento da Produção. Departamento de micro, pequenas e médias empresas. Fórum permanente das microempresas e empresas de pequeno porte, 2007.

MCEVILY, B.; ZAHEER, A. Architects of Trust: The role of network facilitators in geographical clusters. In: Kramer, R. M.; Cook, K. S. (Eds.). Trust and distrust in organizations. New York: Russel Sage Foundation, 2004. p. 189-213.

MENTZER. J. T. et al. Defining Supply Chain Management. Journal of Business Logistics, $v$. 22, n. 2, 2001.

MIGUEL, P.; BRITO, A. L. A Gestão da Cadeia de Suprimentos e sua Conexão com a Visão Relacional da Estratégia. XXXIII Encontro da Associação Nacional de Pós-Graduação e Pesquisa em Administração. Anais..., São Paulo, 2009.

OLSON, M. A lógica da ação coletiva. São Paulo: Edusp, 1999.

PAULRAJ, A.; LADO, A. A.; CHEN, I. J. Interorganizational communication as a relational competency: Antecedents and performance outcomes in collaborative buyer-supplier relationships. Journal of Operations Management, 26, p. 45-64, 2008.

PARKHE, A. Strategic Alliance Structuring: A Game Theoretic and Transaction Cost Examination of Interfirm Cooperation. The Academy of Management Journal, v. 3, n. 3, p. 794-829, Aug. 1993.

PIRANI, S. L.; CUNHA, C. R. A Formação da 
Confiança: Um Estudo no Pool da Unibraspe. Revista de Administração da UFSM, v. 5, n. 1, p. 375-392, 2010.

SIMATUPANG, T. M.; SRIDHARAN, R. The Collaborative Supply Chain. International Journal of Logistics Management, v. 13, n. 1, 2001.

SLACK, N.; CHAMBERS, S.; JOHNSTON, R. Operations Management. 5. ed. Harlow: FT Prentice Hall, 2007.

TORRES JR., A. S.; RATÃO, B. P. Relacionamento na Cadeia de Abastecimento - Estudo de caso de uma Pequena Empresa Distribuidora. Gestão \& Regionalidade, v. 27, n. 79, jan./abr. 2011.

TRIVIÑOS, A. N. S. Introdução à Pesquisa em Ciências Sociais: A pesquisa qualitativa em educação. 3 ed. São Paulo: Atlas, 1987.

VIEIRA, M. M. F.;ZOUAIN, D. M. (Org.). Pesquisa Qualitativa em Administração. Rio de Janeiro: Editora FGV, 2004.

WALTER, S. A.; BACH, T. M. Adeus papel, marcatextos, tesoura e cola: Inovando o processo de análise de conteúdo por meio do ATLAS.ti. XII SEMEAD, Seminário de Administração, São Paulo, Anais..., 2009.

Walter, A.; Ritter, T.; Gemünden, H. G. Value creation in buyer-seller relationships. Industrial Marketing Management, v. 30, n. 4, p. 365377, 2001.

WEBSTER, A. L. Estatística Aplicada à Administração e Economia. São Paulo: McGraw-Hill, 2006.

WEGNER, D. Governança, gestão e capital social em redes horizontais de empresas: uma análise de suas relações com o desempenho das empresas participantes. Tese (Doutorado) - Universidade Federal do Rio Grande do Sul, Porto Alegre, 2011. 